\title{
Hypertension among School going Urban and Rural Adolescents: A Comparative Study \\ Pradhan $B^{1}$, Yadav $A^{2}$,Yadav $K^{3}$,Sankhla $M^{4}$, Raj $D^{5}$,Gaur KL \\ Submission : 10-9-2020 \\ Review : 25-11-2020 \\ Acceptance 14-12-2020
}

1. MBBS Student, SMS Medical College, Jaipur (Rajasthan)

2. Sr. Professor, Department of Physiology, SMS Medical College, Jaipur (Rajasthan)

3. Sr. Demonstrator, Department of Physiology, SMS Medical College, Jaipur (Rajasthan)

4. Assistant Professor, Department of Physiology, Government Medical College, Kota(Rajasthan)

5. Professor, Department of Community Medicine, SMS Medical College, Jaipur (Rajasthan)

6. Sr. Professor, Department of Community Medicine, SMS Medical College, Jaipur (Rajasthan)

Corresponding Author: Dr. Anuradha Yadav

Address of correspondence: Dr. Anuradha Yadav 6/1 Heera bagh flats, Sawai Man Singh Road, Jaipur, Rajasthan, India. PIN-302004 E.Mail: dr.anuradhayadav@yahoo.co.in Mobile No. 09414638469

\section{Abstract}

Background: In the modern society, technology has contributed to create physical comfort in the life and simultaneously, there is alteration in dietary habits of youngsters. This has affected adolescent's health significantly, leading to hypertension in both urban and rural adolescent population.

Objectives: Present study aimed to access and compares the prevalence of hypertension among urban and rural adolescent.

Methods: A community-based cross-sectional comparative study conducted on 300 healthy age matched adolescents, 1019 years of age from each of rural and urban school of Jaipur (Rajasthan). After Institutional Ethical Committee and school administration approval, a predesigned proforma was filled having socio-demographic details, personal and family history. An average blood pressure was calculated by measuring 3 recordings with 5 minutes break through sphygmomanometer. The blood pressure was classified on percentile bases into prehypertension and hypertension. The data inferred by chisquare and ' $p$-value' less than 0.05 considered as significant.

Result: The prevalence of hypertension among urban and rural adolescent of Jaipur was $7.6 \%$ and $7 \%$, while prehypertension was $32 \%$ and $28 \%$, respectively. The prevalence of hypertension was high for systolic than diastolic blood pressure and more in late adolescent than early adolescent age group which was found significant only for systolic hypertension ( $p=0.003)$.

Conclusion: High prevalence of adolescent's hypertension is an important risk factor for future consequences of cardiovascular disease suggesting that there should be change in lifestyle. The early detection and management of it can prevent any future disability and mortality.

Keywords: Adolescents, Hypertension, Pre-hypertension

\section{Introduction}

Hypertension in adolescents is an emerging health problem in developing countries like India as well as developed countries. Pediatric hypertension that has paralleled an increasing prevalence of childhood obesity ${ }^{[1-5]}$. Elevated blood pressure during childhood and adolescence is associated with end-organ damage ${ }^{[6,7]}$, most commonly left ventricular hypertrophy, and is predictive of hypertension in early adulthood ${ }^{[5,8,9]}$.

Some studies reported that adolescents living in urban areas are less prone to hypertension than that of rural areas because of better awareness but other studies are contrary to it, states that adolescents of rural areas are healthier, which is mainly due to healthy lifestyle ${ }^{[10,11]}$. There is also a wide variation in the prevalence of hypertension ${ }^{[12-15]}$. Furthermore, the data related to the prevalence of hypertension among urban and rural adolescent is scanty in Rajasthan.

The present study was hypothesised to assess and compare the proportion of hypertension among urban and rural adolescents.

\section{Methods}

A community-based, cross-sectional, analytic type of observational study was conducted on 600 school children's i.e. 300 school children for each of two groups, after taking approval from the Institutional Ethical Committee and form school administration and consent from parents/ guardians. This present study was conducted to assess and compare measure the blood pressure among adolescents of the urban and rural government school of Jaipur (Rajasthan).

Total 600 healthy age matched adolescents with $10-19$ years of age group were included in this study having 300 children from rural school 300 from urban school in equal number. Students suffering from any acute or chronic disease, secondary hypertension, taking any medications, not willing to participate were excluded from the study. 
A pre-designed questionnaire /working proforma was asked to be filled by each participant that having information regarding demographic details (name, age, gender, address, religion, parental education, parental occupation), family history of chronic diseases (hypertension, diabetes mellitus, ischemic heart disease, cerebro-vascular accidents and any other chronic illness).

The blood pressure was measured on the left arm by using a standard mercury sphygmomanometer, after giving five minutes of rest to participants in sitting posture and taking all the necessary precautions. The appropriate sized cuff was selected with the bladder width about $40 \%$ of the arm circumference at a point mid-way between olecranon and acromion and the bladder length covering at least $80-100 \%$ circumference of the arm ${ }^{[16]}$. Three measurements of systolic blood pressure (SBP) and diastolic blood pressure (DBP) were taken at intervals of five minutes and the average was calculated. This measured average blood pressure was converted into percentile and adolescents were classified into hypertensive, pre-hypertensive and normal categories using the below percentile chart.

The percentile charts based on gender, age and height provided by the National High Blood Pressure Educational Programme (NHBPEP): fourth report was used for the classification of blood pressure ${ }^{[17]}$.

Percentile Chart

A Systolic and/or Diastolic BP Percentile of:

Equal to or greater than the 95th percentile

90th to less than the 95th percentile

BP greater than $120 / 80 \mathrm{~mm} \mathrm{Hg}$

* Readings for Children with BP exceeding 120/80 mm Hg may indicate Stage 1 or Stage 2 hypertension, so putting those $\mathrm{BP}$ readings into the context of percentiles can help a health care provider determine an appropriate treatment

"Prehypertension" is defined as average SBP or DBP levels that are $=90^{\text {th }}$ percentile, but $<95^{\text {th }}$ percentile. Adolescents with BP levels $\geq 120 / 80 \mathrm{mmHg}$ should be considered prehypertensive. Elevated BP constitutes both prehypertension and hypertension.

Statistics: All the Collected data were entered and compiled into excel sheet and statistical analysis were performed using statistical software primer (version-6). The qualitative data are expressed in form of percentage and proportion; the chi-square test was used to infer the significance of proportion. ' $p$-value' less than 0.05 considered as significant.

\section{Results}

The present study was conducted on urban and rural schoolgoing adolescents, covering 300 urban school-going adolescents and another 300 rural school-going adolescent. When compared the prevalence of pre-hypertension and hypertension among urban and rural adolescents, it was more in urban than rural adolescent, with statically non-
Suggests that a child has:

Hypertension (HT)

Prehypertension (pre-HT)

Prehypertension (Elevated) * significant difference (Figure-1).

Although the prevalence of systolic hypertension and prehypertension was more in urban than rural adolescents, but this difference was not found statistically significant (Table 1). While the prevalence of diastolic pre-hypertension was more in rural than urban adolescents, but again the difference in both group was non-significant (Table 2).

Although the late adolescent group seemed more prone to systolic pre-hypertension than early adolescent group in urban population, it was without significant difference (Table 3). The high prevalence was also observed for diastolic prehypertension in urban late adolescent than early adolescent but the difference was again not statistically significant (Table 4).

Younger rural adolescents were having a significantly less systolic prevalence of pre-hypertension than older ones $(p=0.003)$. While the rural young adolescent had less prevalence of diastolic pre-hypertension than older ones with a statistically non-significant difference (Table 3,4 ).

Table 1

Comparison of Systolic Pre-hypertension and Hypertension among Urban and Rural School going Adolescents

\begin{tabular}{|lllll|}
\hline $\begin{array}{l}\text { Classification of } \\
\text { Hypertension }\end{array}$ & $\begin{array}{l}\text { Urban frequency } \\
\text { Number (\%) }\end{array}$ & $\begin{array}{l}\text { Rural frequency } \\
\text { Number (\%) }\end{array}$ & Total & $\begin{array}{l}\text { Significance } \\
\text { p value }\end{array}$ \\
\hline Normal & $189(63 \%)$ & $205(68.33 \%)$ & 394 & $\lambda^{2}=2.065$ \\
\hline Pre-Hypertension & $96(32 \%)$ & $84(28 \%)$ & 180 & $\mathrm{df}=2$ \\
\hline Hypertension & $15(5 \%)$ & $11(3.66 \%)$ & 26 & $\mathrm{p}=0.356$ \\
\hline Total & $300(100 \%)$ & $300(100 \%)$ & 600 & \\
\hline
\end{tabular}


Table 2 Comparison of Dystolic Pre-hypertension and Hypertension among Urban and Rural School going Adolescents

\begin{tabular}{|lllll|}
\hline $\begin{array}{l}\text { Classification of } \\
\text { Hypertension }\end{array}$ & $\begin{array}{l}\text { Urban frequency } \\
\text { Number (\%) }\end{array}$ & $\begin{array}{l}\text { Rural frequency } \\
\text { Number (\%) }\end{array}$ & Total & $\begin{array}{l}\text { Significance } \\
\text { p value }\end{array}$ \\
\hline Normal & $268(89.33 \%)$ & $266(88.66)$ & 534 & $\chi^{2}=0.571$ \\
\hline Pre-Hypertension & $17(5.66 \%)$ & $21(7 \%)$ & 38 & $\mathrm{df}=2$ \\
\hline Hypertension & $15(5 \%)$ & $13(4.33 \%)$ & 28 & $\mathrm{p}=0.751$ \\
\hline Total & $300(100 \%)$ & $300(100 \%)$ & 600 & \\
\hline
\end{tabular}

Table 3 Comparison of Systolic and Diastolic Pre-Hypertension and Hypertension among Urban Early and Late Adolescents

\begin{tabular}{|c|c|c|c|c|}
\hline $\begin{array}{l}\text { Classification of } \\
\text { Hypertension }\end{array}$ & $\begin{array}{l}\text { Early Adolescent } \\
\text { Number (\%) }\end{array}$ & $\begin{array}{l}\text { Late Adolescent } \\
\text { Number (\%) }\end{array}$ & $\begin{array}{l}\text { Total } \\
\mathrm{N}=600\end{array}$ & $\begin{array}{l}\text { Significance } \\
\text { p value }\end{array}$ \\
\hline \multicolumn{5}{|c|}{ Status of Systolic Hypertension } \\
\hline Normal & $122(65.24 \%)$ & $67(59.3 \%)$ & 189 & $\chi^{2}=1.085$ \\
\hline Pre-Hypertension & $56(29.95 \%)$ & $40(35.4 \%)$ & 96 & $d f=2$ \\
\hline Hypertension & $9(4.81 \%)$ & $6(5.3 \%)$ & 15 & $p=0.581$ \\
\hline Total & $187(100 \%)$ & $113(100 \%)$ & 300 & \\
\hline \multicolumn{4}{|c|}{ Status of Diastolic Hypertension } & \multirow{4}{*}{$\begin{array}{l}\chi^{2}=0.734 \\
d f=2 \\
p=0.693\end{array}$} \\
\hline Normal & 169(90.37\%) & $99(87.61 \%)$ & 268 & \\
\hline Pre-Hypertension & $9(4.81 \%)$ & $8(7.07 \%)$ & 17 & \\
\hline Hypertension & $9(4.81 \%)$ & $6(5.3 \%)$ & 15 & \\
\hline Total & $187(100 \%)$ & $113(100 \%)$ & 300 & \\
\hline
\end{tabular}

Early adolescence (10-14 years) and Late adolescence (15-19 years) ${ }^{18}$

Table 4 Comparison of Systolic and Diastolic Pre-Hypertension and Hypertension among Rural Early and Late Adolescents

\begin{tabular}{|c|c|c|c|c|}
\hline $\begin{array}{l}\text { Classification of } \\
\text { Hypertension }\end{array}$ & $\begin{array}{l}\text { Early Adolescent } \\
\text { Number (\%) }\end{array}$ & $\begin{array}{l}\text { Late Adolescent } \\
\text { Number (\%) }\end{array}$ & $\begin{array}{l}\text { Total } \\
\mathrm{N}=600\end{array}$ & $\begin{array}{l}\text { Significance } \\
\text { p value }\end{array}$ \\
\hline \multicolumn{5}{|c|}{ Status of Systolic Hypertension } \\
\hline Normal & $141(75.4 \%)$ & $64(56.63 \%)$ & 205 & $\chi^{2}=11.507$ \\
\hline Pre-Hypertension & $41(21.93 \%)$ & $43(38.05 \%)$ & 84 & DF 2 \\
\hline Hypertension & $5(2.67 \%)$ & $6(5.3 \%)$ & 11 & $p=0.003$ \\
\hline Total & $187(100 \%)$ & $113(100 \%)$ & 300 & \\
\hline \multicolumn{4}{|c|}{ Status of Diastolic Hypertension } & $\chi^{2}=0.471$ \\
\hline Normal & $168(89.83 \%)$ & $98(86.72 \%)$ & 266 & \multirow{3}{*}{$\begin{array}{l}\text { DF } 2 \\
p=0.790\end{array}$} \\
\hline Pre-Hypertension & $11(5.89 \%)$ & $10(8.85 \%)$ & 21 & \\
\hline Hypertension & $8(4.27 \%)$ & $5(4.42 \%)$ & 13 & \\
\hline Total & 187(100\%) & $113(100 \%)$ & 300 & \\
\hline
\end{tabular}




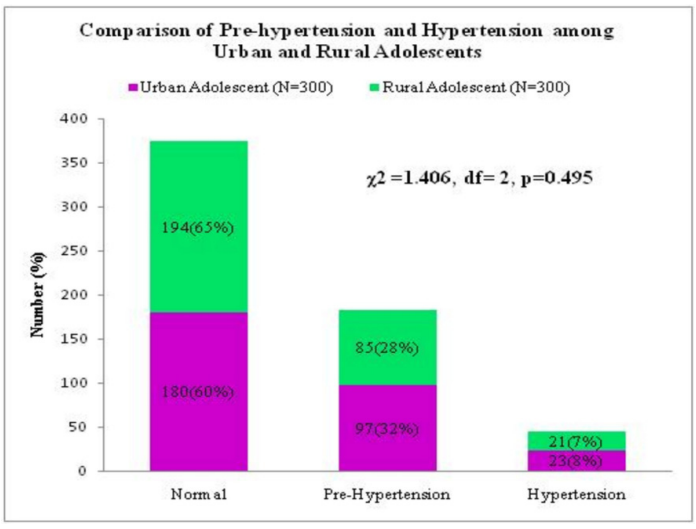

\section{Discussion}

In this study, high prevalence of pre-hypertension and hypertension was found, among both urban and rural adolescents. In the urban adolescent prevalence of hypertension and pre-hypertension was $8 \%$ and $32 \%$, respectively. While in rural adolescents it was $7 \%$ and $28 \%$ for hypertension and pre-hypertension, respectively. In the rural adolescent prevalence of hypertension was comparatively lower than the urban adolescents with a non-significant difference. An increased prevalence of hypertension was found with the increase in age, mainly in rural adolescents with a statistically significant $(P=0.003)$ difference.

In the present study, the prevalence of hypertension was $8 \%$ and $7 \%$ in urban and rural adolescents. Almost similar prevalence was observed by Vendavathy et al ${ }^{[12]}(7.2 \%)$ in Bangalore city, Buch $N$ et al ${ }^{[19]}(6.48 \%)$ at Surat and by $R$. Sharma et al ${ }^{[20]}$ found $8.2 \%$ in central India. Whereas the lower prevalence of hypertension among adolescents was observed by Nihaz $\mathrm{K}^{[15]}(4.5 \%)$ in Kerala. In comparison to present study a high prevalence of hypertension was documented in other studies, Tony L et al ${ }^{[14]}$ found $21.4 \%$ at Thiruvanthanpuam, Sunder JS et al ${ }^{[21]}$ (Chennai) found $22 \%$, prevalence of hypertension. Tony $L$ et al ${ }^{[14]}$ found the prevalence of systolic pre-hypertension $21.4 \%$ and diastolic pre-hypertension $5.3 \%$, while in the present study systolic and diastolic hypertension prevalence same both for urban $(5 \%)$ and rural adolescents (4 $\%$ approx.). In this study, a slight high prevalence of hypertension was found in urban than rural adolescents.

High prevalence of pre-hypertension was found among urban and rural adolescent that is $32 \%$ and $28 \%$, respectively. The high prevalence of pre-hypertension was observed mainly for SBP (32\%-urban, $28 \%$ rural) than DBP (6\% urban, $7 \%$ rural). Similar to present study high prevalence of pre-hypertension (24\%) was also observed in Prasad S et al ${ }^{[22]}$ study conducted at Lucknow. Tanu Anand et al ${ }^{[23]}$ at Delhi found prehypertension prevalence for SBP $4 \%$ and for DBP $26 \%$. While in our study high prevalence of pre-hypertension was observed for SBP in both urban \& rural than DBP. In contrast, to present study, other studies ${ }^{[12,15,21]}$ were found a lower prevalence of pre-hypertension.
In present study, the high prevalence of hypertension and prehypertension was observed among both in urban and rural, but more in urban adolescents due to various factors. The lack of physical activity may be the main factor that contributes to hypertension. The increased stress level with rapid urbanization and changed dietary habits like more fatty and salty diet and less fruit intake also adds on rising blood pressure. The more consumption of salty diet raises the sodium, while fewer intakes of fruits decrease the potassium that contributes to a rise in blood pressure level. The increased stress level stimulates our sympathetic system, which causes vasoconstriction of blood vessels that further aggravate the blood pressure level. Thus, the change in lifestyle is the possible mechanism of a high prevalence of hypertension and pre-hypertension among urban and rural residents of Jaipur.

\section{Limitations:}

1. We were unable to collect data from private schools due to their apprehension.

2. The school children were unable to provide accurate data about their parent's monthly income.

3. Children were also not able to give exact information about their lifestyle like total sleeping hours, duration of exercise in a day, fast food intake etc.

Suggestions: In the present study, participants were from government schools and belong to lower socioeconomic status. If this study has been done to compare government verse reputed private schools, the very high prevalence of blood pressure might be found. As the private schools' adolescents are from high socioeconomic status and prone to high caloric intake and low physical activity.

\section{Conclusion:}

The present study found a high prevalence of hypertension among both urban $(7.66 \%)$ and rural adolescents $(7 \%)$, while the prevalence of pre-hypertension was predominantly high in urban $(32 \%)$ than rural adolescents $(28 \%)$ of Jaipur. Adolescents in the stage of pre-hypertension are on risk for future hypertension identified. The early detection and management reduces the possible morbidity and mortality in future and also the economic burden for family and for the country.

\section{Acknowledgement:}

We would like to thank Kavita Garg, Principal, Government Senior Secondary School, Labana Tehsil, Amer for the field and data management. We would also like to thank the students for their participation

\section{REFERENCES}

1. Muntner P, He J, Cutler JA, Wildman RP, Whelton PK. Trends in blood pressure among children and adolescents JAMA 2004; 291: 2107-2113. 
2. Din-Dzietham R, Liu Y, Bielo MV, Shamsa F. High blood pressure trends in children and adolescents in national surveys, 1963 to 2002. Circulation 2007; 116: 1488-1496.

3. Sorof JM, Lai D, Turner J, Poffenbarger T, Portman RJ. Overweight, ethnicity, and the prevalence of hypertension in school-aged children. Pediatrics 2004; 113: 475-482.

4. Falkner B, Daniels SR. Summary of the Fourth Report on the Diagnosis, Evaluation, and Treatment of High Blood Pressure in Children and Adolescents. Hypertension 2004; 44: 387-388.

5. National High Blood Pressure Education Program Working Group on High Blood Pressure in Children and Adolescents. The fourth report on the diagnosis, evaluation, and treatment of high blood pressure in children and adolescents. Pediatrics 2004; 114: 555-576.

6. Daniels SR, Loggie JM, Khoury P, Kimball TR. Left ventricular geometry and severe left ventricular hypertrophy in children and adolescents with essential hypertension. Circulation 1998; 97: 1907-1911.

7. Sorof JM, Alexandrov AV, Cardwell G, Portman RJ. Carotid artery intimal-medial thickness and left ventricular hypertrophy in children with elevated blood pressure. Pediatrics 2003; 111: 61-66.

8. Bao W, Threefoot SA, Srinivasan SR, Berenson GS. Essential hypertension predicted by tracking of elevated blood pressure from childhood to adulthood: the Bogalusa Heart Study. Am J Hypertens 1995; 8: 657-665.

9. Chen X, Wang Y. Tracking of blood pressure from childhood to adulthood: a systematic review and metaregression analysis. Circulation 2008; 117: 3171-3180

10. Ratovoson $\mathrm{R}$, Rasetarinera $\mathrm{O} R$, Andrianantenaina I, Rogier C, Piola P, Pacaud P Hypertension, a Neglected Disease in Rural and Urban Areas in Moramanga, Madagascar. PLoS ONE 2015; 10(9): e0137408.

11. Ravikumar V. Baradol, S.V.Patil, Anand Ranagol. Prevalance of overweight, obesity and hypertension amongst school children and adolescents in North Karnataka: A cross sectional study. Int J Med Sci Public Health 2014; 4(3): 260-64.

12. Vedavathy S. and Sangamesh S. Prevalence of hypertension in urban school going adolescents of Bangalore, India. International Journal of Contemporary Pediatrics 2016; 3(2):416-423.

13. Amrin Y. Tadvi and Janardhan R. Bandi. Study of prevalence of hypertension in young adult population of age group 20 to 40 years in an urban slum of Mumbai,
Maharashtra, India. Int J Community Med Public Health 2016; 3: 3325-3331.

14. Tony L, Areekal B, Nair ATS, Ramachandran R, Philip RR, Rajasi RS, et al. Prevalence of hypertension and prehypertension among adolescent school children in Thiruvananthapuram, Kerala, India. Int J Community Med Public Health 2016; 3:3556-63.

15. Naha, N., John, M., \& Cherian, V. Prevalence of hypertension and risk factors among school children in Kerala, India. .Int J Contemp Pediatr. 2016; 3(3): 931-938.

16. Pickering TG, Hall JE, Appel LJ, Falkner BE, Graves J, Hill $\mathrm{MN}$, et al. Recommendations for blood pressure measurement in humans and experimental animals: Blood pressure measurement in humans. Circulation. 2005; 111: 697-716.

17. US Preventive Services Task Force, Barton M. Screening for obesity in children and adolescents: US preventive services task force recommendation statement. Pediatrics 2010; 125:361-7.

18. Alexa C. Curtis. Defining adolescence. Journal of Adolescent and Family Health. 2015; 7(2):27.

19. Buch N, Goyal JP, Kumar N, Parmar I, Shah VB, Charan J. Prevalence of hypertension in school going children of Surat city, Western India. J Cardiovasc Dis Res 2011; 2:22832.

20. Sharma R, Mandliya J, Dhaneria M, Tiwari H L. Prevalence of hypertension in mid adolescents in central India: A school based comparative study. Int J Med Res Rev 2015; 3 (8):891-899.

21. Sundar JS, Adaikalam JMS, Parameswari S, Valarmarthi S, Kalpana S, et al. Prevalence and Determinants of Hypertension among Urban School Children in the Age Group of 13- 17 Years in, Chennai, Tamilnadu. Epidemiol 2013; 3:130.

22. Prasad S, Masood J, Srivastava AK, Mishra P. Elevated blood pressure and its associated risk factors among adolescents of a North Indian City - A cross-sectional study. Indian J Community Med 2017; 42: 155-8.

23. Anand T, Ingle GK, Meena GS, Kishore J, Kumar R.. Hypertension and Its Correlates among School Adolescents in Delhi. Int J Prev Med. 2014 ; 5(1): S65S70.

How to cite this article : Pradhan B, Yadav A,Yadav K,Sankhla M, Raj D,Gaur KL. Hypertension among School going Urban and Rural Adolescents: A Comparative Study. Perspectives in Medical Research 2020; 8 (3):39-43.

DOI: 10.47799/pimr.0803.09

Sources of Support: Nil, Conflict of interest: None declared 